\title{
Anti-predator defences of a bombardier beetle: is bombing essential for successful escape from frogs?
}

\author{
Shinji Sugiura ${ }^{\text {Corresp. } 1}$ \\ ${ }^{1}$ Graduate School of Agricultural Science, Kobe University, Kobe, Japan \\ Corresponding Author: Shinji Sugiura \\ Email address: ssugiura@people.kobe-u.ac.jp
}

Some animals, such as the bombardier beetles (Coleoptera: Carabidae: Brachinini), have evolved chemical defences against predators. When attacked, bombardier beetles can discharge noxious chemicals at temperatures of approximately $100^{\circ} \mathrm{C}$ from the tip of their abdomens, "bombing" their attackers. Although many studies to date have investigated how bombardier beetles discharge defensive chemicals against predators, relatively little research has examined how predators modify their attacks on bombardier beetles to avoid being bombed. In this study, I observed the black-spotted pond frog Pelophylax nigromaculatus (Anura: Ranidae) attacking the bombardier beetle Pheropsophus jessoensis under laboratory conditions. In Japan, Pe. nigromaculatus is a generalist predator in grasslands where the bombardier beetle frequently occurs. Almost all the frogs (92.9\%) observed rejected live bombardier beetles; $67.9 \%$ stopped their attacks once their tongues touched the beetles, and $25.0 \%$ spat out the beetles immediately after taking the beetles into their mouths. No beetle bombed a frog before being taken into a frog's mouth. All beetles taken into mouths bombed the frogs. Only $7.1 \%$ of the frogs swallowed live bombardier beetles after being bombed in the mouth. When dead beetles were provided instead, $85.7 \%$ of the frogs rejected the dead beetles, $71.4 \%$ stopped their attacks after their tongues touched the beetles, and $14.3 \%$ spat out the beetles. Only $14.3 \%$ of the frogs swallowed the dead beetles. The results suggest that the frogs tended to stop their predatory attack before receiving a bombing response from the beetles. Therefore, bombing was not essential for the beetles to successfully defend against the frogs. Using its tongue, Pe. nigromaculatus may be able to rapidly detect a deterrent chemical or physical characteristics of its potential prey Ph. jessoensis and thus avoid injury by stopping its predatory attack before the beetle bombs it. 


\section{Anti-predator defences of a bombardier beetle: is bombing essential}

2 for successful escape from frogs?

3

4 Shinji Sugiura

5

6 Graduate School of Agricultural Science, Kobe University, Kobe, Japan

7

8 Corresponding author: S. Sugiura, ssugiura@people.kobe-u.ac.jp, sugiura.shinji@gmail.com

9

10 Running title: Bombardier beetle defences against frogs

11 


\section{ABSTRACT}

13 Some animals, such as the bombardier beetles (Coleoptera: Carabidae: Brachinini), have evolved 14 chemical defences against predators. When attacked, bombardier beetles can discharge noxious 15 chemicals at temperatures of approximately $100^{\circ} \mathrm{C}$ from the tip of their abdomens, "bombing" 16 their attackers. Although many studies to date have investigated how bombardier beetles

17 discharge defensive chemicals against predators, relatively little research has examined how 18 predators modify their attacks on bombardier beetles to avoid being bombed. In this study, I 19 observed the black-spotted pond frog Pelophylax nigromaculatus (Anura: Ranidae) attacking the

20 bombardier beetle Pheropsophus jessoensis under laboratory conditions. In Japan, Pe.

21 nigromaculatus is a generalist predator in grasslands where the bombardier beetle frequently

22 occurs. Almost all the frogs (92.9\%) observed rejected live bombardier beetles; 67.9\% stopped

23 their attacks once their tongues touched the beetles, and $25.0 \%$ spat out the beetles immediately

24 after taking the beetles into their mouths. No beetle bombed a frog before being taken into a

25 frog's mouth. All beetles taken into mouths bombed the frogs. Only $7.1 \%$ of the frogs swallowed

26 live bombardier beetles after being bombed in the mouth. When dead beetles were provided

27 instead, $85.7 \%$ of the frogs rejected the dead beetles, $71.4 \%$ stopped their attacks after their

28 tongues touched the beetles, and $14.3 \%$ spat out the beetles. Only $14.3 \%$ of the frogs swallowed

29 the dead beetles. The results suggest that the frogs tended to stop their predatory attack before 30 receiving a bombing response from the beetles. Therefore, bombing was not essential for the

31 beetles to successfully defend against the frogs. Using its tongue, Pe. nigromaculatus may be

32 able to rapidly detect a deterrent chemical or physical characteristics of its potential prey $P h$.

33 jessoensis and thus avoid injury by stopping its predatory attack before the beetle bombs it.

35 INTRODUCTION 
37 Physical and chemical defences have evolved in many organisms to protect against natural 38 enemies (Edmunds, 1974; Eisner, Eisner \& Siegler, 2005). For example, some plant and animal 39 species have developed physical deterrents such as thorns and spines (Edmunds, 1974; Cooper \&

40 Owen-Smith, 1986; Eisner, 2003; Sugiura \& Yamazaki, 2014; Sugiura, 2016; Ito, Taniguchi \&

41 Billen, 2016), while other species produce defensive chemicals, including toxic substances, to

42 prevent themselves from being eaten (Eisner, 2003; Eisner, Eisner \& Siegler, 2005; Derby, 2007;

43 Mithöfer \& Boland, 2012). Organisms whose defence mechanisms can cause severe injury to

44 their natural enemies have also evolved warning signals, such as conspicuous body colouration

45 or particular sounds (Lev-Yadun, 2001; Ruxton, Sherratt \& Speed, 2004; Inbar \& Lev-Yadun,

46 2005; Bonacci et al., 2008; Lev-Yadun, 2009; Bura et al., 2016; Sugiura \& Takanashi, 2018). In

47 response, predators have evolved specific abilities to avoid such well-defended prey by

48 recognising warning colouration or detecting chemical signals (Edmunds, 1974; Endler, 1991;

49 Ruxton, Sherratt \& Speed, 2004; Skelhorn \& Rowe, 2006; Williams et al., 2010).

50 Adult bombardier beetles (Coleoptera: Carabidae: Brachinini) bomb, i.e. discharge noxious

51 chemicals from the tip of their abdomens at temperatures of approximately $100^{\circ} \mathrm{C}$, when they are

52 disturbed or attacked (Aneshansley et al., 1969; Dean, 1979; Eisner, 2003; Eisner, Eisner \&

53 Siegler, 2005; Arndt et. al., 2015). Such ejection of hot chemicals is only known in the

54 coleopteran family Carabidae. Previous studies have investigated how bombardier beetles

55 successfully defend against predators (Eisner, 1958; Eisner \& Meinwald, 1966; Eisner \& Dean,

56 1976; Dean, 1980a; Eisner, Eisner \& Aneshansley, 2005; Eisner et al., 2006). Bombardier

57 beetles can aim their abdominal discharge in virtually any direction, spraying various parts of

58 their own bodies (e.g., legs and dorsal surface) with the toxic chemicals (Eisner \& Aneshansley,

59 1999). Dean (1980b) reported that predators displayed intense responses to the unheated 
60 chemical discharges of bombardier beetles in experiments. This suggests that the cooled

61 chemicals coating the beetles' body surfaces function as the primary defence against predators.

62 Successful defence mediated by chemicals on the body surfaces of beetles may reduce the costs

63 of spraying (bombing). Further research is needed to clarify the relative importance of chemical

64 toxicity and heat for overall successful anti-predatory defence.

65 Frogs and toads are important predators of carabid beetles (Larochelle, 1974a,b). However,

66 bombardier beetles have rarely been found in the gut contents and faeces of frogs and toads

67 (Larochelle, 1974a,b; Sarashina, Yoshihisa \& Yoshida, 2011; except Mori, 2008), suggesting

68 that bombing prevents toads and frogs from swallowing and ingesting beetles (Eisner \&

69 Meinwald, 1966; Dean, 1980a; Esiner, 2003; Sugiura \& Sato, 2018). Still, only a few studies

70 have investigated the factors that cause anuran predators to stop preying on bombardier beetles

71 (Dean, 1980b). Elucidating these ecological factors would contribute to a better understanding of

72 the evolution of anti-predatory defences in insects.

73 This study aims to investigate the responses of the black-spotted pond frog Pelophylax

74 nigromaculatus (Hallowell) (Anura: Ranidae) to the defensive behaviour of the bombardier

75 beetle Pheropsophus jessoensis (Morawitz). Pheropsophus jessoensis is a bombardier beetle

76 found in East Asia (Ueno et al., 1985; Jung et al., 2012); the beetle is a common inhabitant of

77 farmlands, grasslands, and forest edges in Japan (Habu \& Sadanaga, 1965; Ueno et al., 1985;

78 Yahiro et al., 1992; Ishitani \& Yano, 1994; Fujisawa et al., 2012; Ohwaki et al., 2015; Sugiura \&

79 Sato, 2018). Adult Ph. jessoensis eject toxic chemicals (1,4-benzoquinone and 2-methyl-1,4-

80 benzoquinone) at a temperature of approximately $100^{\circ} \mathrm{C}$ from their rear ends in response to

81 predator attacks (Video S1; Kanehisa and Murase, 1977; Kanehisa, 1996). Pelophylax

82 nigromaculatus is a true frog inhabiting wetlands and farmlands of East Asia (Liu et al., 2010;

83 Tsuji et al., 2011; Komaki et al., 2015), being one of the most abundant frog species of 
84 traditional agricultural landscapes including farmlands, grasslands, and forest edges (Hirai, 2002;

85 Honma, Oku \& Nishida, 2006; Tsuji et al., 2011; Matsuhashi \& Okuyama, 2015). Using its

86

87

88

89

90

91

92

93

94

95

96

97

103

104

105

106

107

tongue, Pe. nigromaculatus readily catches and swallows smaller prey (Video S2; Honma, Oku \& Nishida, 2006). Pelophylax nigromaculatus is a generalist predator that has been reported to prey on carabid beetles (Maeda \& Matsui, 1999; Hirai \& Matsui, 1999; Sano \& Shinohara, 2011; Sarashina, Yoshihisa \& Yoshida, 2011). As Ph.jessoensis and Pe. nigromaculatus co-occur in the same grassland habitats, this frog species is a potential predator of adult Ph.jessoensis. In early June 2016, I offered an adult Ph.jessoensis to an adult Pe.nigromaculatus under laboratory conditions. The frog attacked the beetle, but stopped the attack immediately after its tongue touched the beetle. No bombing sounds were heard, suggesting that the frog ceased its attack before the beetle bombed. Therefore, I hypothesised that bombing is not essential when $P h$. jessoensis seeks to avoid being swallowed by Pe. nigromaculatus. To test this hypothesis, I observed Pe. nigromaculatus attacking Ph.jessoensis under laboratory conditions using a digital video camera. Acceptance or rejection of prey was carefully investigated using slow-motion videos. Furthermore, both dead and live beetles were used to test whether bombing is essential for successful defence against predatory attacks by Pe. nigromaculatus. Finally, I discuss the importance of primary and secondary defences in terms of overall anti-predation defence.

\section{MATERIALS AND METHODS}

\section{Sampling}

Approximately 100 adult $P h$. jessoensis were collected from grasslands and forest edges in Kato $\left(34^{\circ} 54^{\prime} \mathrm{N}, 135^{\circ} 02^{\prime} \mathrm{E}, 120 \mathrm{~m}\right.$ above sea level), Hyogo Prefecture, central Japan, from May to 
108 August in 2016, 2017, and 2018 (cf. Sugiura \& Sato, 2018). Body weight was measured to the

109 nearest $0.1 \mathrm{mg}$ using an electronic balance (PA64JP, Ohaus, Tokyo, Japan). Study individuals

110 were maintained separately in plastic cases (diameter: $85 \mathrm{~mm}$; height: $25 \mathrm{~mm}$ ) with wet tissue

111 paper in the laboratory at $25^{\circ} \mathrm{C}$. Dead larvae of Spodoptera litura (Fabricius) (Lepidoptera:

112 Noctuidae) were provided as food (Sugiura \& Sato, 2018). Beetles were not used repeatedly in

113 different feeding experiments. All experiments were conducted $22.6 \pm 4.0$ (means \pm standard

114 errors; range: 4-69) days after the beetles were collected.

115 Approximately 100 individuals of Pe. nigromaculatus were collected from wetlands and

116 forest edges in Takarazuka-shi $\left(34^{\circ} 53^{\prime} \mathrm{N}, 135^{\circ} 17^{\prime} \mathrm{E}, 230 \mathrm{~m}\right.$ above sea level), Sanda-shi $\left(34^{\circ} 57^{\prime} \mathrm{N}\right.$,

$117135^{\circ} 11^{\prime} \mathrm{E}, 180 \mathrm{~m}$ above sea level), and Sayo-cho $\left(35^{\circ} 02^{\prime} \mathrm{N}, 134^{\circ} 20^{\prime} \mathrm{E}, 180 \mathrm{~m}\right.$ above sea level),

118 Hyogo Prefecture, central Japan, from May to August in 2016, 2017, and 2018. The distances

119 between these sites and the sampling site of Ph.jessoensis ranged from 15.6 to $65.4 \mathrm{~km}$.

120 Although Pe. nigromaculatus has recently been classified as near threatened (NT) in the

121 Japanese Red Data List (Ministry of the Environment of Japan, 2017), this species was abundant

122 at the collection sites. Both juveniles and adults were collected. Body weight was measured to

123 the closest $0.01 \mathrm{~g}$ using an electronic balance (EK-120A, A\&D, Tokyo). Small and large frogs

124 were maintained separately in small $(120 \times 85 \times 130 \mathrm{~mm}$, length $\times$ width $\times$ height $)$ and large

125 plastic cages $(120 \times 185 \times 130 \mathrm{~mm}$, length $\times$ width $\times$ height $)$, respectively, in the laboratory at

$12625^{\circ} \mathrm{C}$. Live larvae of S. litura, Tenebrio molitor Linnaeus (Coleoptera: Tenebrionidae), and

127 Zophobas atratus Fabricius (Coleoptera: Tenebrionidae) were provided as food. Frogs were

128 starved for $24 \mathrm{~h}$ before the feeding experiments to standardise their hunger level (cf. Honma,

129 Oku \& Nishida, 2006). As with the beetles, individual frogs were not used repeatedly. The

130 experiments were conducted $18.6 \pm 2.5$ (means \pm standard errors; range: 4-66) days after the

131 frogs were collected. The frogs were released after the experiments were completed. 


\section{Feeding experiments}

135 Feeding experiments were all conducted at $25^{\circ} \mathrm{C}$. To start, a frog was placed in a transparent

136 plastic container $(120 \times 85 \times 130 \mathrm{~mm}$, length $\times$ width $\times$ height $)$. Then, a transparent glass petri

137 dish (45 $\mathrm{mm}$ in diameter, $15 \mathrm{~mm}$ in height) containing a live bombardier beetle was placed

138 outside the plastic container where the frog could see it. Frogs that did not try to attack the beetle

139 (34.1\%) were not used for the feeding experiments. However, frogs that ignored Ph.jessoensis

140 did not respond to other prey (i.e. T. molitor larvae). If a frog displayed attacking behaviour (i.e.

141 opening the mouth and shooting out the tongue to capture prey; Video S2), a live beetle was then

142 placed in the container with the frog. The resulting behaviours were recorded on video using a

143 digital camera (iPhone 6 plus, Apple) at 240 frames per second. If the frog did not swallow the

144 beetle, palatable prey (a T. molitor larva) was offered to the frog several minutes after beetle

145 rejection to determine whether the frog was hungry. If a frog swallowed the beetle, I observed

146 whether it vomited the beetle within 330 min of swallowing it (cf. Sugiura \& Sato, 2018).

147 Vomited beetles were checked to see whether they were still alive. Frogs that did not vomit after

148 swallowing were considered to have digested the beetle. Frog faeces were examined after the

149 experiment to confirm whether the beetles were digested. In total, 28 frogs and 28 live

150 bombardier beetles were used in the experiments. The means \pm standard errors of the frog and

151 live beetle body weights were $10.23 \pm 1.39 \mathrm{~g}(n=28)$ and $213.0 \pm 10.0 \mathrm{mg}(n=28)$, respectively.

153 A second set of frogs were presented with dead adult beetles to test whether the bombing 154 response is essential for deterring a predatory attack. Pelophylax nigromaculatus usually does 155 not attack motionless prey. However, in a pilot test, an individual of Pe. nigromaculatus attacked 
156 and ingested a dead caterpillar (S. litura) when forceps were used to move the caterpillar within

157 the frog's field of view. For this experiment, the bombardier beetles were killed in a freezer at $158-15^{\circ} \mathrm{C}$. First, a dead beetle was placed in the plastic container $(120 \times 85 \times 130 \mathrm{~mm}$, length $\times$

159 width $\times$ height) within the frog's field of view. If the frog did not initially respond to the beetle,

160 forceps were used to move the dead beetle within the frog's field of view again. Frogs that did

161 not attack the dead beetles $(29.2 \%)$ were not used in these experiments; frogs that ignored $P h$.

162 jessoensis did not respond to other prey (i.e., T. molitor larvae). The predatory behaviours of the

163 frogs were recorded using the same digital video camera. Frogs that did not swallow dead beetles

164 were offered T. molitor larvae several minutes after beetle rejection to check whether they were

165 hungry. Twenty-eight frogs and 28 dead beetles were used in this experiment. The means \pm

166 standard errors of the frog and dead beetle body weights were $8.65 \pm 1.25 \mathrm{~g}(n=28)$ and $214.8 \pm$

$1677.6 \mathrm{mg}(n=28)$, respectively. The mean body weight of frogs that attacked dead beetles did not

168 differ significantly from the mean body weight of frogs that attacked live beetles $(t$-test, $t=0.84$,

$169 P=0.40)$. The mean body weight of dead beetles did not differ significantly from the mean body

170 weight of live beetles ( $t$-test, $t=-0.14, P=0.89)$

171 Videos of frogs responding to live and dead beetles were played back using QuickTime

172 Player version 10.4 (Apple, Inc.). Frog responses to the bombardier beetles were grouped into

173 four categories (cf. Ito, Taniguchi \& Billen, 2016; Matsubara \& Sugiura, 2017; Sugiura \& Sato,

174 2018): (1) frogs that touched the beetles with their tongues but did not take the beetles into their

175 mouths; (2) frogs that spat out the beetles after taking them into the mouth; (3) frogs that

176 swallowed beetles but vomited them later; and (4) frogs that swallowed and digested the beetles.

177 I also assessed whether frogs that rejected beetles (1-2) resumed their attacks within 10 seconds.

178 All experiments were performed in accordance with the Kobe University Animal

179 Experimentation Regulations (Kobe University Animal Care and Use Committee, 27-01, 30-01). 
180 No frogs were seriously injured or killed during the feeding experiments. My study also

181 complies with the current laws of Japan.

182

183 Data analysis

184

185 Generalised linear models (GLMs) featuring binomial error distributions and logit links (i.e.,

186 logistic regressions) were used to identify factors that contributed to frogs' successful

187 swallowing and digestion of the bombardier beetles. The success or failure (1/0) of frogs'

188 swallowing and digesting beetles was used as the response variable. Frog weight, beetle weight,

189 the frog weight $\times$ beetle weight interaction, and beetle condition (live or dead) were treated as

190 fixed factors. When the residual deviance was 1.5-fold larger (overdispersion) or smaller

191 (underdispersion) than the residual degrees of freedom, a quasi-binomial error distribution was

192 used rather than a binomial error distribution. Furthermore, fixed factors were subjected to

193 likelihood ratio testing when marginal significance was evident. Thus, the significance of models

194 with and without the factors of interest were compared using the GLMs. All analyses were

195 performed using R ver. 3.3.2 (R Development Core Team 2016).

196

197 RESULTS

198

199 In the experiment using live adult bombardier beetles $(n=28), 26$ frogs $(92.9 \%)$ rejected the

200 beetles without swallowing them (Fig. 1); 19 frogs (67.9\%) stopped attacking the beetles

201 immediately after touching the beetles with their tongues (Fig. 2; Video S3), and 7 frogs (25.0\%)

202 spat out the beetles after taking the beetles into their mouths (Fig. 3; Video S4). No beetle

203 bombed a frog before being taken into the frog's mouth. All beetles that were taken into frog 
204 mouths bombed (Video S4). Only two frogs (7.1\%) were observed to swallow the bombardier

205 beetles (Table 1) after being bombed in the mouth; one of the frogs successfully digested the

206 beetle, but the other frog vomited the beetle $18 \mathrm{~min}$ after swallowing it (Table 1). The vomited

207 beetle was still alive. Of the frogs that took the beetles into their mouths, $88.9 \%(n=8 / 9)$

208 initially stopped attacking the beetles when their tongues first touched the beetles, but resumed

209 their predatory attack soon thereafter (Fig. 3; Video S4). Frogs that did not swallow beetles

210 consumed other prey (i.e., T. molitor larvae) soon thereafter.

211 When dead beetles were used $(n=28), 24$ frogs $(85.7 \%)$ rejected the dead beetles without

212 swallowing them (Fig. 1); 20 frogs (71.4\%) stopped attacking the beetles after their tongues

213 touched the dead beetles (Video S5), and 4 frogs (14.3\%) spat out the beetles after taking the

214 beetles into their mouths (Fig. 1). Only 4 frogs (14.3\%) swallowed the dead beetles. Similar to

215 the experiment using live beetles, $87.5 \%$ of the frogs that took beetles into their mouths $(n=7 / 8)$

216 were initially deterred when their tongues first touched the beetles, but continued with their

217 predatory behaviour soon afterwards. The frogs that did not swallow beetles ate other prey (i.e.,

218 T. molitor larvae) soon thereafter.

219 The proportion of dead beetles swallowed by frogs (14.3\%) was higher than that of live

220 beetles (7.1\%). However, the GLM results indicated that the frog swallowing rates of live and

221 dead beetles did not significantly differ (Table 1). Whether beetles were swallowed or not was

222 associated with beetle size, but not frog size (Table 1). Beetles were more likely to be swallowed

223 as beetle size decreased (Fig. 4A). The interaction of frog and beetle weight was not significant

224 (Fig. 4A).

225 The proportion of dead beetles digested by frogs (14.3\%) was higher than the proportion of

226 live beetles swallowed (3.6\%). The GLMs indicated that the difference between the digestion

227 rates of live and dead beetles was significant (Table 2). Beetle size affected the digestion rate 
228 (Table 2, Fig. 4B).

229

\section{DISUSSION}

231

232 Here, I found that Pe.nigromaculatus frequently rejected Ph.jessoensis without attempting to 233 swallow the beetles (Fig. 1). Around 70\% of frogs stopped attacking both live and dead beetles

234 immediately after touching the beetles with their tongues. Although the high-speed release of hot 235 noxious chemicals (bombing) protected Ph. jessoensis from digestion by the frog $P e$.

236 nigromaculatus (Figs. 1, 3; Video S4), my findings support the hypothesis that bombing is not 237 essential for Ph. jessoensis to successfully evade being swallowed by Pe. nigromaculatus (Figs. 238 1, 3; Video S3). Which factors, then, stopped the frogs from attacking? Three potential reasons

239 can be considered: (1) the frogs recognised the warning colouration of the beetles; (2) the body

240 size of the beetles was too large for the frog to accommodate; and (3) the frogs reflexively

241 avoided the beetles after detecting toxic substances or other deterrent characteristics on the

242 beetles' body surfaces.

243 The bombardier beetle Ph. jessoensis does have a striking yellow and black pattern on its 244 body that could serve as warning colouration (Fig. 1), although this has not been empirically 245 demonstrated. Anuran predators can avoid toxic prey by recognising certain colours or other 246 morphological characteristics and then ignoring those prey (Brower, Brower \& Westcott, 1960;

247 Brower \& Brower, 1962; Dean, 1980a; Taniguchi et al., 2005; Ito, Taniguchi \& Billen, 2016). In 248 fact, 34.1 and $29.2 \%$ of frogs did not seek to attack live or dead beetles, respectively, before the 249 feeding experiments commenced, suggesting that Pe.nigromaculatus may recognise the body 250 pattern and shape of $\mathrm{Ph}$. jessoensis and interpret these as warning signals. However, frogs that 251 ignored Ph. jessoensis did not respond to other prey (i.e., T. molitor larvae). Therefore, the 
252 experimental conditions used may not be appropriate for analysing foraging by certain frogs.

253 Alternatively, the yellow-and-black pattern of $P h$. jessoensis may serve as disruptive

254 camouflage; flightless $P h$. jessoensis walk on soil of forest edges, grasslands, and agricultural

255 fields. Further work is needed to explore the significance of Ph. jessoensis colour as a defensive 256 trait.

257 GLM analysis indicated that beetle size was correlated with beetle-swallowing frequency of

258 frogs (Table 1). Pelophylax nigromaculatus has been reported to spit out large prey that they

259 were unable to swallow after taking the prey into their mouths (Honma, 2004; Honma, Oku \&

260 Nishida, 2006). However, $67.9 \%$ of the frogs in the experiment with live beetles and $71.4 \%$ of

261 the frogs in the experiment with dead beetles stopped their predatory attacks before taking the

262 beetles into their mouths (Fig. 1, 2; Video 3, 5). Thus, my results do not provide strong evidence

263 that the frogs could not ingest large beetles. Rather, the amount of chemicals on the beetle body

264 surface may increase with beetle size (see below).

265 The rapid responses of the frog species Pe. nigromaculatus to bombardier beetles (Fig. 2)

266 could be considered a reflex action of the frogs' tongues (cf. Kumai, 1981a, b; Hirakawa, 1989).

267 Frogs are known to use their tongues as a chemical detector (Dean, 1980b; Kumai, 1981a, b;

268 Barlow, 1998) as well as a prey-catching tool (Noel et al., 2017). For example, chemical or

269 electrical stimulation of the tongue can generate reflex responses in Pe. nigromaculatus (Kusano

270 \& Sato, 1957; Kumai, 1981a, b; Suzuki \& Nomura, 1985; Takeuchi, Satou \& Ueda, 1986;

271 Hirakawa, 1989). Because Pe. nigromaculatus is a generalist predator that can attack a variety of

272 arthropods within its field of view (Hirai \& Matsui, 1999; Honma, 2004; Honma, Oku \& Nishida,

273 2006; Sano \& Shinohara, 2011; Sarashina, Yoshihisa \& Yoshida, 2011), Pe. nigromaculatus

274 may have evolved specific responses to toxic prey to avoid being injured by trying to eat them.

275 The results of this study suggest that the tongues of Pe. nigromaculatus may be able to rapidly 
276 detect toxic substances or other characteristics on the body surface of the bombardier beetles,

277 and the frogs subsequently avoid the beetles to prevent themselves from being bombed and

278 injured. Previous studies have focused on how frogs and toads use their tongues to catch prey

279 (Ewert, 1970; Nishikawa \& Gans, 1996; Monroy \& Nishikawa, 2010; Noel et al., 2017). Few

280 reports have explored how frogs and toads use their tongues to detect toxins in/on potential prey

281 (but see Dean, 1980b). Therefore, the tongue responses that I describe in Pe. nigromaculatus will

282 likely be evident in other frogs such as the tree frog Hyla japonica (Günther) (Taniguchi et al.,

283 2005; Ito, Taniguchi \& Billen, 2016; Matsubara \& Sugiura, 2017).

284

285 CONCLUSIONS

286

287 In one study, the chemicals produced by bombardier beetles' bombing did not stimulate the 288 tongues of toads any less intensely than did the heat from the chemical reaction (Dean, 1980b).

Other than this study, the relative importance of the toxic chemicals and heat produced by bombing for the successful escape of bombardier beetles from predators has been largely unexplored. My results support the hypothesis that bombing is not essential when bombardier beetles defend themselves against frog attacks. Furthermore, my findings suggest that (cool) toxic chemicals on the beetles' bodies alone may cause frogs to desist from an attack; thus, chemicals on the body may serve as a primary defence and bombing as a secondary defence. Successful defence by chemicals on the body would reduce the costs associated with bombing, suggesting that beetles may have evolved to use chemicals on the body surface as their primary defence. However, further experiments are required to validate this hypothesis; for example, dead beetles with body surfaces cleaned of chemicals, or palatable prey coated with toxic

299 chemicals, should be offered to frogs. 
300 Many prey animals exhibit multiple anti-predator defences (Edmunds, 1974). Predation

301 pressures imposed by different enemies may encourage prey to diversify defence strategies.

302 Further studies are needed.

303

304 ACKNOWLEDGEMENTS

305 I am grateful to K. Sakagami, K. Uchida, and A. Ushimaru for providing valuable information

306 about the collection sites. I thank K. Sakagami, W. Higashikawa, and M. Ito for helping to

307 collect the study animals, and S. Matsubara and Y. Maeda for helping to maintain them. T.

308 Takanashi provided valuable advice on this research. M. Bulbert and two anonymous reviewers

309 provided helpful comments on an earlier version of the manuscript.

310

311 ADDITIONAL INFORMATION AND DECLARATIONS

312 Data Availability

313 The following information was supplied regarding data availability:

314 Raw data is available from the Figshare Digital Repository

315 (https://figshare.com/s/734fc893bcaadfde3a90).

316

317 Supplemental Information

318 Supplemental information for this article can be found online at http://dx.doi.org/

320 REFERENCES

321

322 Aneshansley DT, Eisner T, Widom JM, Widom B. 1969. Biochemistry at $100^{\circ} \mathrm{C}$ : explosive secretory discharge of bombardier beetles (Brachinus). Science 165:61-63. DOI 
10.1126/science.165.3888.61.

325 Arndt EM, Moore W, Lee WK, Ortiz C. 2015. Mechanistic origins of bombardier beetle

326 (Brachinini) explosion-induced defensive spray pulsation. Science 348:563-567. DOI 10.1126/science. 1261166 .

328

329

330

331

332

333

334

335

336

Bonacci T, Aloise G, Brandmayr P, Brandmayr TZ, Capula M. 2008. Testing the predatory behaviour of Podarcis sicula (Reptilia: Lacertidae) towards aposematic and nonaposematic preys. Amphibia-Reptilia 29: 449-453. DOI 10.1163/156853808785111986.

Barlow LA. 1998. The biology of amphibian taste. In: Heatwole H, Dawley E, eds. Amphibian biology, volume 3: sensory perception. Chipping Norton, Australia: Surrey Beatty \& Sons, $743-782$.

Brower JVZ, Brower LP. 1962. Experimental studies of mimicry. 6. The reaction of toads (Bufo terrestris) to honeybees (Apis mellifera) and their dronefly mimics (Eristalis vinetorum). The American Naturalist 96:297-307. DOI 10.1086/282237.

Brower LP, Brower JVZ, Westcott PW. 1960. Experimental studies of mimicry. 5. The reactions of toads (Bufo terrestris) to bumblebees (Bombus americanorum) and their robberfly mimics (Mallophora bomboides), with a discussion of aggressive mimicry. The American Naturalist 94:343-355. DOI 10.1086/282137.

Bura BL, Kawahara A, Yack J. 2016. A comparative analysis of sonic defences in Bombycoidea caterpillars. Scientific Reports 6:31469. DOI 10.1038/srep31469.

Cooper SM, Owen-Smith N. 1986. Effects of plant spinescence on large mammalian herbivores. Oecologia 68:446-455. DOI 10.1007/BF01036753.

Dean J. 1979. Defensive reaction time of bombardier beetles: an investigation of the speed of a chemical defense. Journal of Chemical Ecology 5:691-701. DOI 10.1007/BF00986554.

Dean J. 1980a. Encounters between bombardier beetles and two species of toads (Bufo 
americanus, B. marinus): speed of prey-capture does not determine success. Journal of Comparative Physiology 133:41-50. DOI 10.1007/BF00660180.

350

351

352

353

354

355

356

357

358

359

360

361

362

363

364

365

366

367

368

369

370

371

Dean J. 1980b. Effects of thermal and chemical components of bombardier beetle chemical defense: glossopharyngeal response in two species of toads (Bufo americanus, B. marinus). Journal of Comparative Physiology 133:51-59. DOI 10.1007/BF00660181.

Derby CD. 2007. Escape by inking and secreting: marine molluscs avoid predators through a rich array of chemicals and mechanisms. Biological Bulletin 213:274-289. DOI $10.2307 / 25066645$.

Edmunds M. 1974. Defense in animals. Harlow: Longman.

Eisner T. 1958. The protective role of the spray mechanism of the bombardier beetle, Brachynus ballistarius Lec. Journal of Insect Physiology 2:215-220.

Eisner T. 2003. For love of insects. Cambridge: The Belknap Press of the Harvard University Press.

Eisner T, Aneshansley DJ. 1999. Spray aiming in the bombardier beetle: Photographic evidence. Proceeding of the National Academy of Sciences USA 96:9705-9709. DOI 10.1073/pnas.96.17.9705.

Eisner T, Dean J. 1976. Ploy and counterploy in predator-prey interactions: Orb-weaving spiders versus bombardier beetles. Proceeding of the National Academy of Sciences USA 73:1365-1367. DOI 10.1073/pnas.96.17.9705.

Eisner T, Meinwald J. 1966. Defensive secretions of arthropods. Science 153:1341-1350. DOI 10.1126/science.153.3742.1341.

Eisner T, Eisner M, Aneshansley DJ. 2005. Pre-ingestive treatment of bombardier beetles by jays: food preparation by "anting" and "sand-wiping”. Chemoecology 15:227-233. DOI $10.1007 / \mathrm{s} 00049-005-0316-6$. 
372 Eisner T, Eisner M, Siegler M. 2005. Secret weapons: defenses of insects, spiders, scorpions,

373 and other many-legged creatures. Cambridge: The Belknap Press of the Harvard

$374 \quad$ University Press.

375 Eisner T, Aneshansley DJ, del Campo ML, Eisner M, Frank JH, Deyrup M. 2006. Effect of

376 bombardier beetle spray on a wolf spider: repellency and leg autotomy. Chemoecology

377 16:185-189. DOI 10.1007/s00049-006-0346-8.

378 Endler JA. 1991. Interactions between predators and prey. In: Krebs JR, Davies NB, eds.

379 Behavioural ecology : an evolutionary approach. London, Paris, Berlin, Vienna: Blackwell,

$380 \quad 169-196$

381 Ewert JP. 1970. Neural mechanisms of prey-catching and avoidance behaviour in the toad (Bufo bufo L.). Brain, Behavior and Evolution 3:36-56. DOI 10.1159/000125462.

383 Fujisawa T, Lee CM, Ishii M. 2012. Species diversity of ground beetle assemblages in the 384 distinctive landscapes of the Yodo River flowing through northern Osaka Prefecture, 385 central Japan. Japanese Journal of Environmental Entomology and Zoology 23:89-100. DOI 10.11257/jjeez.23.89.

Habu A, Sadanaga K. 1965. Illustrations for identification of larvae of the Carabidae found in cultivated fields and paddy-fields (III). Bulletin of the National Institute of Agricultural Sciences, Series C: Plant Pathology and Entomology 19:81-216 (in Japanese).

Hirai T. 2002. Ontogenetic change in the diet of the pond frog, Rana nigromaculata. Ecological Research 17:639-644. DOI 10.1046/j.1440-1703.2002.00521.x.

392 Hirai T, Matsui M. 1999. Feeding habits of the pond frog, Rana nigromaculata, inhabiting rice 393 fields in Kyoto, Japan. Copeia 1999:940-947. DOI 10.2307/1447969.

394 Hirakawa T. 1989. A Study of averaged waves of reflex discharges in the frog hypoglossal 395 nerve elicited by electrical stimulation of glossopharyngeal afferent. Journal of the Kyushu 
Dental Society 43:693-709. (in Japanese with English summary). DOI 10.2504/kds.43.693.

397

398

399

Honma A. 2004. MOMO VideoArchives: momo040902cj01b. http://movspec.musnh.city.osaka.jp/ethol/showdetail.php?movieid=momo040902cj01b. Accessed: 28 January 2018.

Honma A, Oku S, Nishida T. 2006. Adaptive significance of death feigning posture as a specialized inducible defence against gape-limited predators. Proceedings of the Royal Society B: Biological Science 273:1631-1636. DOI 10.1098/rspb.2006.3501.

Inbar M, Lev-Yadun S. 2005. Conspicuous and aposematic spines in the animal kingdom. Naturwissenschaften 92:170-172. DOI 10.1007/s00114-005-0608-2.

Ishitani M, Yano K. 1994. Species composition and seasonal activities of ground beetles (Coleoptera) in a fig orchard. Japanese Journal of Entomology 62:201-210.

Ito F, Taniguchi K, Billen J. 2016. Defensive function of petiole spines in queens and workers of the formicine ant Polyrhachis lamellidens (Hymenoptera: Formicidae) against an ant predator, the Japanese tree frog Hyla japonica. Asian Myrmecology 8:1-6. DOI 10.20362/am.008014.

Jung JK, Kim ST, Lee SY, Park CK, Lee EH, Lee JH. 2012. Ground beetle (Coleoptera: Carabidae) assemblage in the urban landscape, Korea. Journal of Ecology and Field Biology 35:79-89. DOI 10.5141/JEFB.2012.012.

Kanehisa K. 1996. Secretion of defensive substance by Carabidae and Brachinidae. Bulletin of the Research Institute for Bioresources, Okayama University 4:9-23 (in Japanese with English summary).

Kanehisa K, Murase M. 1977. Comparative study of the pygidial defensive systems of carabid beetles. Applied Entomology and Zoology 12:225-235. DOI 10.1303/aez.12.225.

Komaki S, Igawa T, Lin SM, Tojo K, Min MS, Sumida M. 2015. Robust molecular 
phylogeny and palaeodistribution modelling resolve a complex evolutionary history:

421 glacial cycling drove recurrent mtDNA introgression among Pelophylax frogs in East Asia. Journal of Biogeography 42:2159-2171. DOI 10.1111/jbi.12584.

423

424

425

426

427

428

431

432

433

434

435

436

437

438

439

440

441

442

443

Kumai T. 1981a. Reflex response of the hypoglossal nerve induced by gustatory stimulation of the frog tongue. Brain Research 208:432-435. DOI 10.1016/0006-8993(81)90572-2.

Kumai T. 1981b. Reflex response of the hypoglossal nerve induced by chemical stimulation of the tongue and electrical stimulation of the glossopharyngeal nerve in the frog. Japanese Journal of Physiology 31:625-637. DOI 10.2170/jjphysiol.31.625.

Kusano K, Sato M. 1957. Properties of fungiform papillae in frog's tongue. Japanese Journal of Physiology 157:324-338. DOI 10.2170/jjphysiol.7.324

Larochelle A. 1974a. The American toad as champion carabid beetle collector. The Pan-Pacic Entomologist 50:203-204.

Larochelle A. 1974b. Carabid beetles (Coleoptera: Carabidae) as prey of North American frogs. The Great Lakes Entomolosit 7:147-148.

Lev-Yadun S. 2001. Aposematic (warning) coloration associated with thorns in higher plants. Journal of Theoretical Biology 210:385-388 DOI 10.1006/jtbi.2001.2315.

Lev-Yadun S. 2009. Aposematic (warning) coloration in plants. In: Baluska F, ed. Plantenvironment interactions. From sensory plant biology to active plant behavior. Berlin: Springer-Verlag, 167-202 DOI 10.1007/978-3-540-89230-4_10.

Liu K, Wang F, Chen W, Tu L, Min MS, Bi K, Fu J. 2010. Rampant historical mitochondrial genome introgression between two species of green pond frogs, Pelophylax nigromaculatus and P. plancyi. BMC Evolutionary Biology 10:201. DOI 10.1186/14712148-10-201.

Maeda N, Matsui M. 1999. Frogs and toads of Japan: revised edition. Tokyo: Bun-ichi Sogo 
$444 \quad$ Shuppan.

445 Matsubara S, Sugiura S. 2017. Chemical defence of turnip sawfly larvae against Japanese tree 446 frogs. Journal of Asia-Pacific Entomology 20:225-227. DOI 10.1016/j.aspen.2017.01.001.

447 Matsuhashi T, Okuyama F. 2015. Frogs and toads of Japan. Tokyo, Japan: Yamakei (in $448 \quad$ Japanese).

449 Monroy JA, Nishikawa K. 2010. Prey capture in frogs: alternative strategies, biomechanical $450 \quad$ trade-offs, and hierarchical decision making. Journal of Experimental Zoology 315:61-71. DOI 10.1002/jez.601

Mori I. 2008. Predation by introduced bullfrog Rana catesbeiana on a breeding male of Rhacophorus schlegelii and the other animals. Bulletin of the Okayama Prefecture Nature Conservation Center 16:61-62 (in Japanese).

455

456

Nishikawa KC, Gans C. 1996. Mechanisms of tongue protraction and narial closure in the marine toad Bufo marinus. Journal of Experimental Biology 199:2511-2529.

Mithöfer A, Boland W. 2012. Plant defense against herbivores: chemical aspects. Annual Review of Plant Biology 63:431-450. DOI 10.1146/annurev-arplant-042110-103854.

Noel AC, Guo HY, Mandica M, Hu DL. 2017. Frogs use a viscoelastic tongue and nonNewtonian saliva to catch prey. Journal of the Royal Society Interface 14: 20160764. DOI 10.1098/rsif.2016.0764.

Ohwaki A, Kaneko Y, Ikeda H. 2015. Seasonal variability in the response of ground beetles (Coleoptera: Carabidae) to a forest edge in a heterogeneous agricultural landscape in Japan. European Journal of Entomology 112:135-144. DOI 10.14411/eje.2015.022.

R Development Core Team. 2016. $R$, a language and environment for statistical computing. Vienna: R Foundation for Statistical Computing.

Ruxton GD, Sherratt TN, Speed MP. 2004. Avoiding attack: the evolutionary ecology of 

crypsis, aposematism, and mimicry. Oxford: Oxford University Press.

469

470

471

472

473

474

475

476

477

478

479

480

481

482

483

484

485

486

487

488

489

490

491

Sano M, Shinohara M. 2011. Species comparison of frogs food habits during mating seasons in Uenohara, Yamanashi Pref., Japan. Bulletin of Teikyo University of Science and Technology 8:101-111 (in Japanese with English summary).

Sarashina M, Yoshihisa Y, Yoshida T. 2011. Stomach contents of invasive Black-spotted Pond frog (Rana nigromaculata) in urban landscape of Sapporo City. Journal of Rakuno Gakuen University 36:81-86 (in Japanese with English summary).

Skelhorn J, Rowe C. 2006. Taste-rejection by predators and the evolution of unpalatability in prey. Behavioral Ecology and Sociobiology 60:550-555. DOI 10.1007/s00265-006-0199-8.

Sugiura S. 2016. Bagworm bags as portable armour against invertebrate predators. PeerJ 4:e1686 DOI 10.7717/peerj.1686.

Sugiura S, Sato T. 2018. Successful escape of bombardier beetles from predator digestive systems. Biology Letters 14:20170647. DOI 10.1098/rsbl.2017.0647.

Sugiura S, Takanashi T. 2018. Hornworm counterattacks: Defensive strikes and sound production in response to invertebrate attackers. Biological Journal of the Linnean Society. DOI 10.1093/biolinnean/blx156.

Sugiura S, Yamazaki K. 2014. Caterpillar hair as a physical barrier against invertebrate predators. Behavioral Ecology 25:975-983. DOI 10.1093/beheco/aru080.

Suzuki H, Nomura H. 1985. Input-output relation in gustatory linguo-hypoglossal reflex in the frog. Matsumoto Shigaku: Journal of the Matsumoto Dental College Society 11:13-17. (in Japanese with English summary).

Takeuchi H, Satou M, Ueda K. 1986. EMG analysis of head muscle during naturally-occurring and electrically- evoked snapping, rejecting and avoiding behavior in the Japanese toad. Zoological Science 3:992. 
492 Taniguchi K, Maruyama M, Ichikawa T, Ito F. 2005. A case of Batesian mimicry between

493

494

495

496

497

498

499

500

501

502

503

504

505

506

507

508

myrmecophilous staphylinid beetle, Pella comes, and its host ant, Lasius (Dendrolasius) spathepus: an experiment using the Japanese tree frog Hyla japonica as a real predator. Insectes Sociaux 52:320-322. DOI 10.1007/s00040-005-0813-1.

Tsuji M, Ushimaru A, Osawa T, Mitsuhashi H. 2011. Paddy-associated frog declines via urbanization: A test of the dispersal-dependent-decline hypothesis. Landscape and Urban Planning 103:318-325. DOI 10.1016/j.landurbplan.2011.08.005.

Ueno S, Kurosawa Y, Sato M (eds). 1985. The Coleoptera of Japan in color vol. II. Osaka, Japan: Hoikusha (in Japanese).

Williams BL, Hanifin CT, Brodie ED Jr, Brodie ED III. 2010. Tetrodotoxin affects survival probability of rough-skinned newts (Taricha granulosa) faced with TTX-resistant garter snake predators (Thamnophis sirtalis). Chemoecology 20:285-290. DOI 10.1007/s00049010-0057-z.

Yahiro K, Fujimoto T, Tokuda M, Yano K. 1992. Species composition and seasonal abundance of ground beetles (Coleoptera) in paddy fields. Japanese Journal of Entomology 60:805-813. 


\section{Figure legend}

510

511 Figure 1 Behavioural responses of the black-spotted pond frog Pelophylax nigromaculatus to

512 live and dead adult individuals of the bombardier beetle Pheropsophus jessoensis. 'Stop attack':

513 the frogs stopped their attacks after their tongues touched the beetles. 'Spit out': the frogs spat

514 out the beetles immediately after taking the beetles into their mouths. 'Swallow': the frogs

515 successfully swallowed the beetles. 'Bombing': the beetles could be heard bombing. Photo

516 credit: Shinji Sugiura.

517

518 Figure 2 Temporal sequence of the frog Pelophylax nigromaculatus rejecting a live adult

519 Pheropsophus jessoensis without taking the beetle into its mouth. The frog stopped the attack

520 immediately after its tongue touched the beetle. No bombing sounds were heard (see Video S3).

521 Credit: Shinji Sugiura.

522

523 Figure 3 Temporal sequence of the frog Pelophylax nigromaculatus spitting out a live adult

524 Pheropsophus jessoensis after taking the beetle into its mouth. Bombing by the beetle was

525 audible just before the frog spat out the beetle (E-F: 1675-1800 ms; see Video S4). Credit:

526 Shinji Sugiura.

527

528 Figure 4. Body size relationships between predator frogs (Pelophylax nigromaculatus) and prey

529 beetles (Pheropsophus jessoensis). (A) Success or failure of swallowing by frogs. (B) Success or

530 failure of digestion by frogs. Closed circles and triangles indicate the swallow (or digestion)

531 success of live and dead beetles, respectively. Open circles and triangles indicate the swallow (or

532 digestion) failure of live and dead beetles, respectively. Photo credit: Shinji Sugiura. 


\section{Supplemental Information}

534

535 Video S1 An adult Pheropsophus jessoensis bombing. The beetle discharged toxic chemicals

536 when the body was stimulated with a pair of forceps. Credit: Shinji Sugiura.

537

538 Video S2. The frog Pelophylax nigromaculatus preying on a carabid beetle. The frog opened

539 its mouth and shot out its tongue to capture prey. Credit: Shinji Sugiura.

540

541 Video S3 The frog Pelophylax nigromaculatus rejecting a live Pheropsophus jessoensis. The

542 frog stopped the attack immediately after its tongue touched the beetle. Credit: Shinji Sugiura.

543

544 Video S4 The frog Pelophylax nigromaculatus spitting out a live Pheropsophus jessoensis. The

545 frog took the beetle into its mouth but immediately spat out the beetle. Credit: Shinji Sugiura.

546

547 Video S5 The frog Pelophylax nigromaculatus rejecting a dead Pheropsophus jessoensis. The

548 frog stopped its attack immediately after its tongue touched the dead beetle. Credit: Shinji

549 Sugiura. 


\section{Table $\mathbf{1}$ (on next page)}

Table 1. Results of a generalised linear model (GLM) testing potential factors influencing whether the frog Pelophylax nigromaculatus successfully swallowed the bombardier beetle Pheropsophus jessoensis in feeding experiments. 
Table 1. Results of a generalised linear model (GLM) testing potential factors influencing whether the frog Pelophylax nigromaculatus successfully swallowed the bombardier beetle Pheropsophus jessoensis in feeding experiments.

\begin{tabular}{llcccc}
\hline Response variable & Explanatory variable (fixed effect) & Coefficient estimate & SE & $t$ value & $P$ value \\
\hline Swallowing success ${ }^{1)}$ & Intercept & 7.601881 & 4.454207 & 1.707 & 0.094 \\
& Frog weight & -0.420817 & 0.290774 & -1.447 & 0.154 \\
& Beetle weight & -0.060781 & 0.025084 & -2.423 & 0.019 \\
& Frog weight $\times$ Beetle weight & 0.002637 & 0.001457 & 1.81 & $0.076{ }^{3)}$ \\
& Beetle treatment ${ }^{2)}$ & 1.387536 & 0.855616 & 1.622 & 0.111 \\
\hline
\end{tabular}

2 1) As the residual deviance was 1.5-fold smaller than the residual degrees of freedom, a quasi-binomial error distribution (rather than a 3 binomial error distribution) was employed. Two and four live and dead beetles, respectively, were swallowed.

$4{ }^{2)}$ Live beetles were used as a reference.

5 3) The significance of this factor was checked using the likelihood ratio test $(P=0.063)$. 


\section{Table 2 (on next page)}

Table 2. Results of a generalised linear model (GLM) testing potential factors influencing whether the frog Pelophylax nigromaculatus successfully digested the bombardier beetle Pheropsophus jessoensis in feeding experiments. 
Table 2. Results of a generalised linear model (GLM) testing potential factors influencing whether the frog Pelophylax nigromaculatus successfully digested the bombardier beetle Pheropsophus jessoensis in feeding experiments.

\begin{tabular}{llccccc}
\hline Response variable & Explanatory variable (fixed effect) & Coefficient estimate & SE & $t$ value & $P$ value \\
\hline Digestion success ${ }^{1)}$ & Intercept & 4.471889 & 4.45551 & 1.004 & 0.32 \\
& Frog weight & -0.370908 & 0.30261 & -1.226 & 0.226 \\
& Beetle weight & -0.04681 & 0.023848 & -1.963 & $0.055^{3)}$ & 0.117 \\
& Frog weight $\times$ Beetle weight & 0.002329 & 0.00146 & 1.596 & 0.057 ) \\
& Beetle treatment ${ }^{2)}$ & 2.011385 & 1.033049 & 1.947 & 0.967 \\
\hline
\end{tabular}

2 1) As the residual deviance was 1.5-fold smaller than the residual degrees of freedom, a quasi-binomial error distribution (rather than a 3 binomial error distribution) was employed. One and four live and dead beetles, respectively, were digested.

$4{ }^{2)}$ Live beetles were used as a reference.

5 3) The significance of this factor was checked using the likelihood ratio test $(P=0.028)$.

$6{ }^{4)}$ The significance of this factor was checked using the likelihood ratio test $(P=0.029)$. 


\section{Figure 1}

Behavioural responses of the black-spotted pond frog Pelophylax nigromaculatus to live and dead adult individuals of the bombardier beetle Pheropsophus jessoensis.

'Stop attack': the frogs stopped their attacks after their tongues touched the beetles. 'Spit out': the frogs spat out the beetles immediately after taking the beetles into their mouths. 'Swallow': the frogs successfully swallowed the beetles. 'Bombing': the beetles could be heard bombing. Photo credit: Shinji Sugiura.

Frog responses

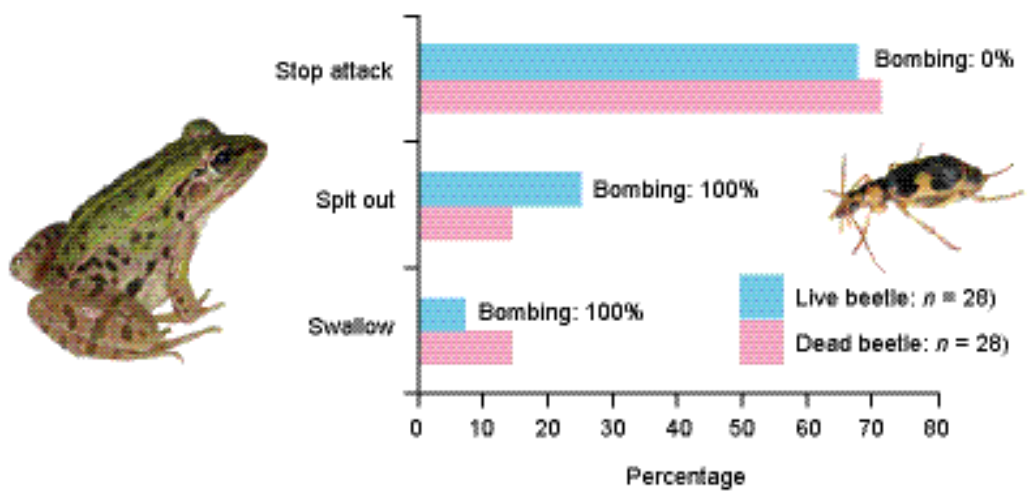


Figure 2

Temporal sequence of the frog Pelophylax nigromaculatus rejecting a live adult Pheropsophus jessoensis without taking the beetle into its mouth.

The frog stopped the attack immediately after its tongue touched the beetle. No bombing sounds were heard (see Video S3). Credit: Shinji Sugiura. 

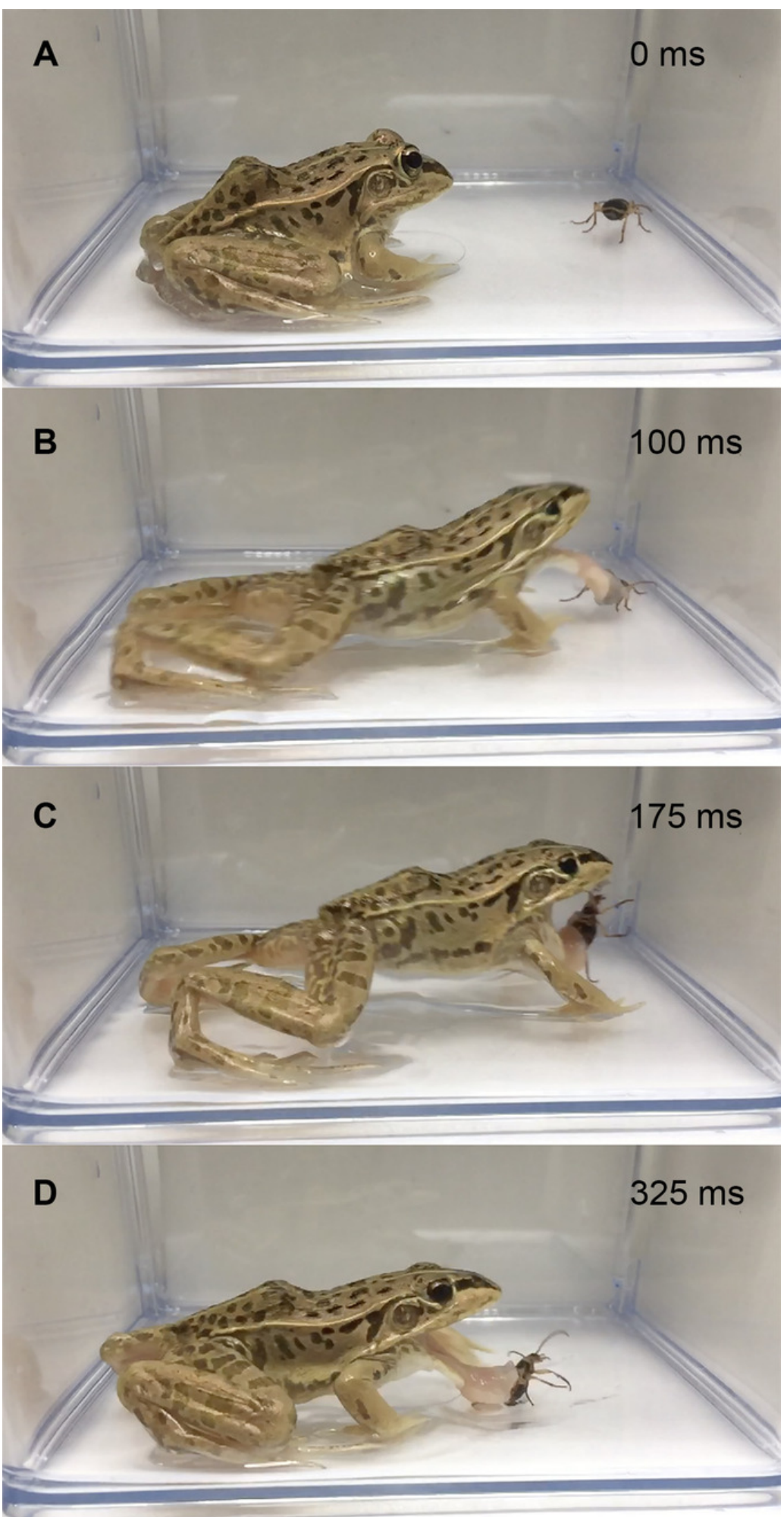

E
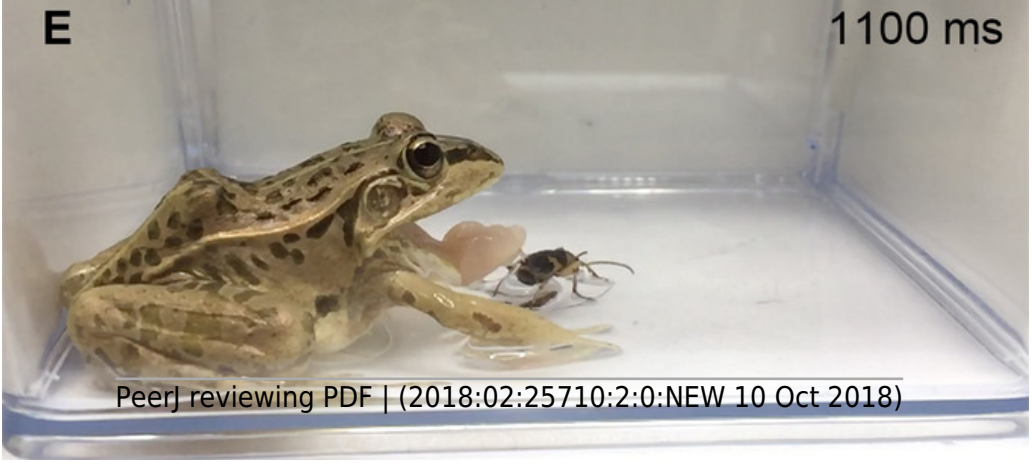


\section{Figure 3}

Temporal sequence of the frog Pelophylax nigromaculatus spitting out a live adult Pheropsophus jessoensis after taking the beetle into its mouth.

Bombing by the beetle was audible just before the frog spat out the beetle (1675-1800 ms; see Video S4). Credit: Shinji Sugiura. 


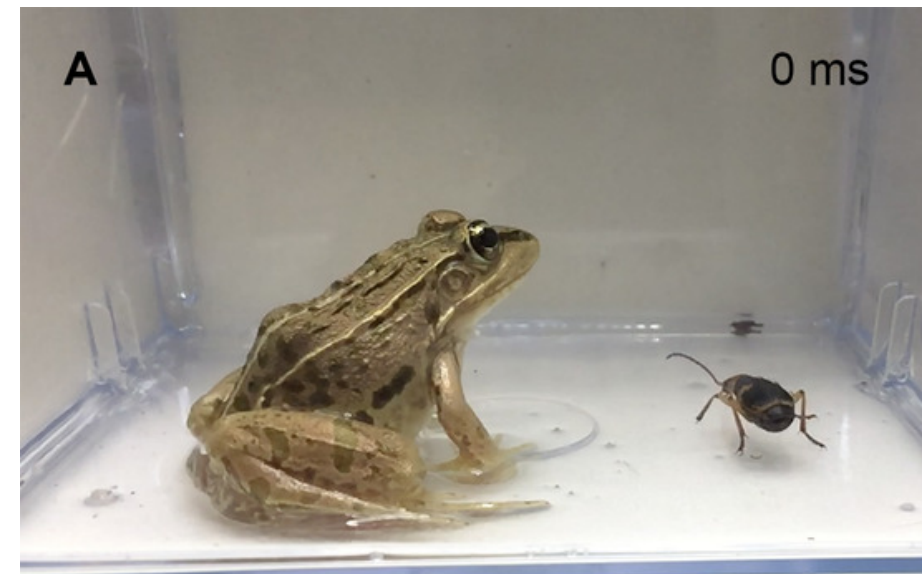

E

$1675 \mathrm{~ms}$
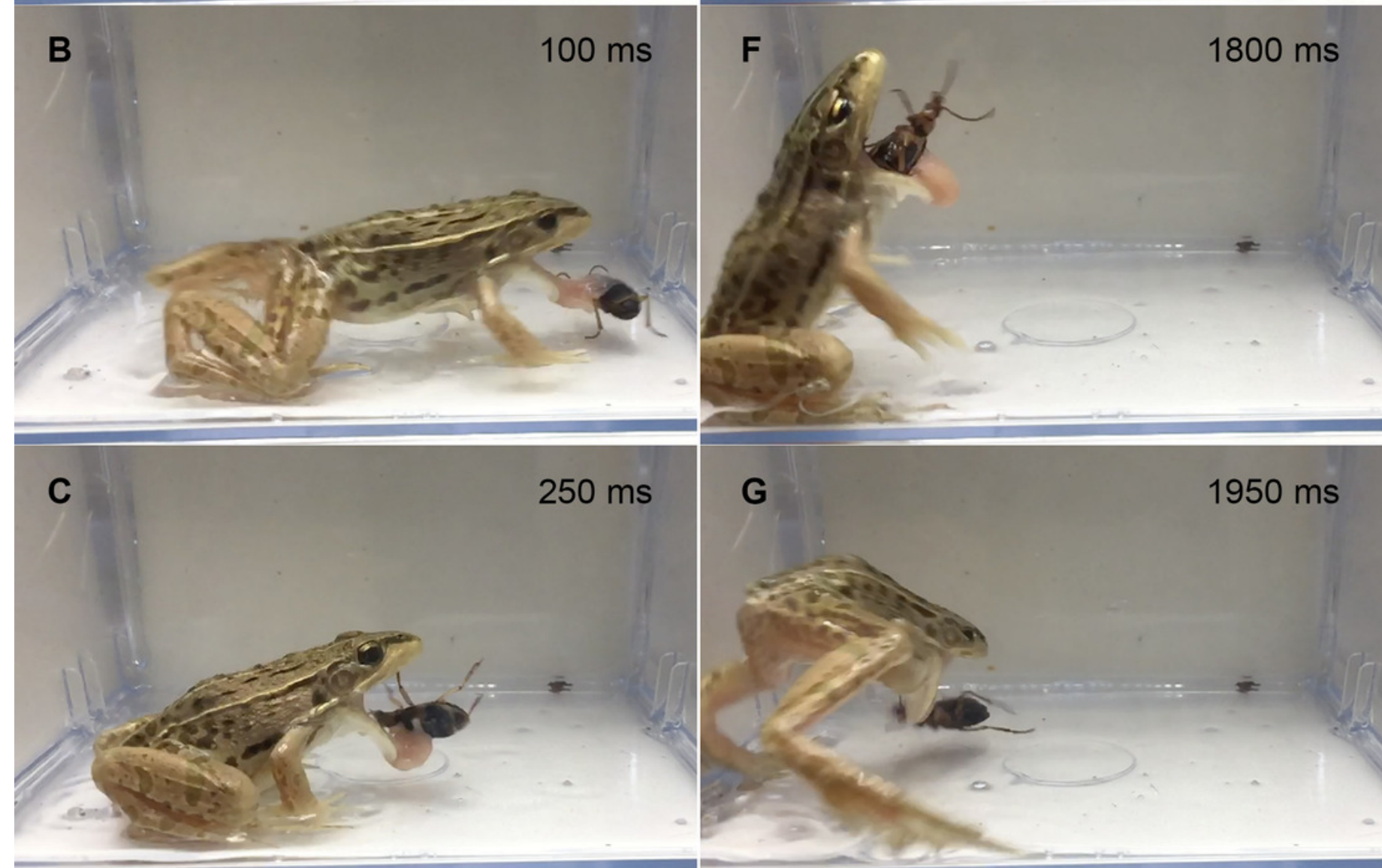

G

1950 ms
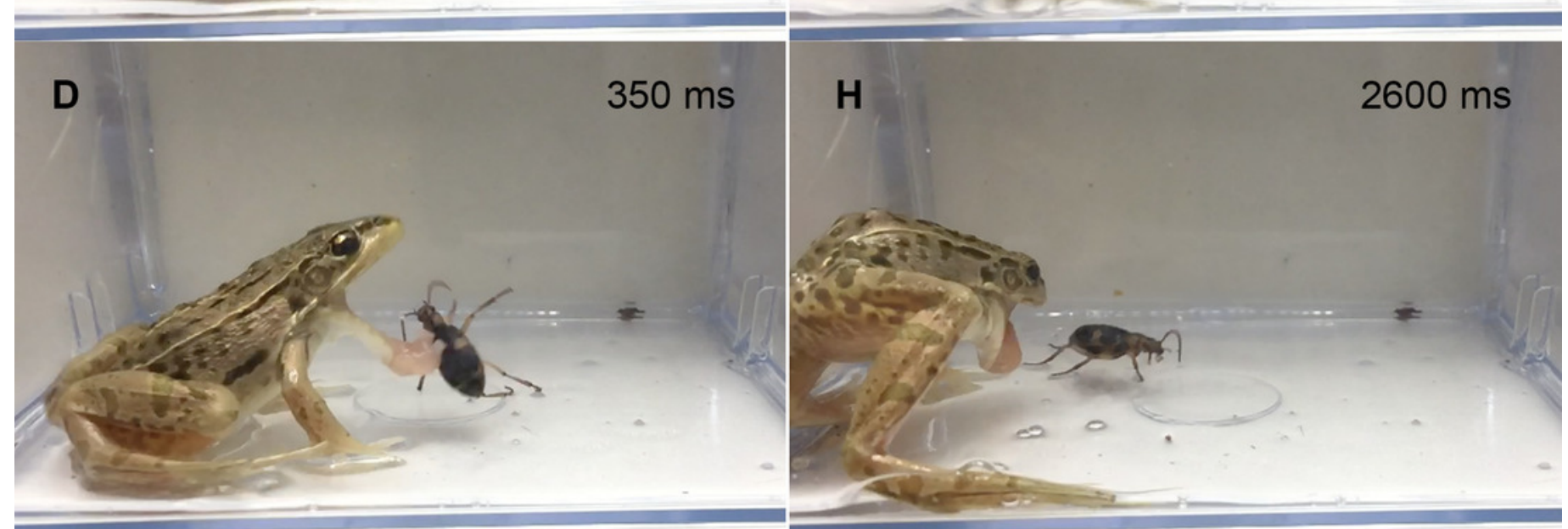


\section{Figure 4}

Body size relationships between predator frogs (Pelophylax nigromaculatus) and prey beetles (Pheropsophus jessoensis).

(A) Success or failure of swallowing by frogs. (B) Success or failure of digestion by frogs. Closed circles and triangles indicate the swallow (or digestion) success of live and dead beetles, respectively. Open circles and triangles indicate the swallow (or digestion) failure of live and dead beetles, respectively. Photo credit: Shinji Sugiura.
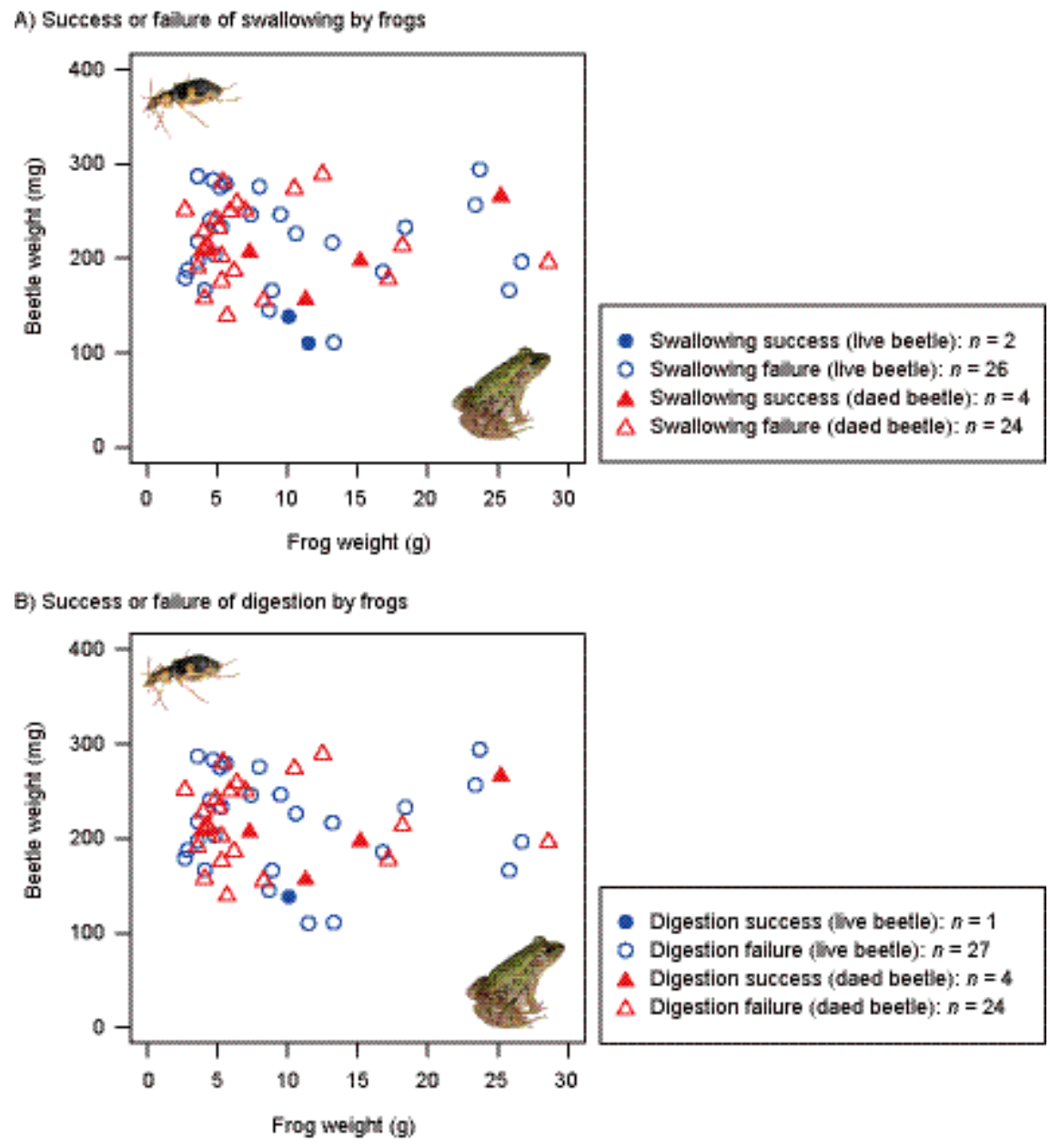